\title{
Test Anxiety in the Foreign Language Learning Context: A Theoretical
}

\section{Framework}

\author{
${ }^{a}$ Ferdane Denkci Akkaş (D) b Selami Aydın (D) c Asiye Baştürk Beydilli \\ ${ }^{\mathrm{d}}$ Tülin Türnük (D) and ${ }^{\mathrm{e}}$ İlknur Saydam
}

\begin{abstract}
a Assist. Prof. Dr., İstanbul Medeniyet University, İstanbul, Turkey, ferdane.denkci@medeniyet.edu.tr b Prof. Dr., İstanbul Medeniyet University, İstanbul, Turkey, selami.aydin@medeniyet.edu.tr c Instructor, İstanbul Medeniyet University, İstanbul, Turkey, asiye.basturk@medeniyet.edu.tr d Instructor, İstanbul Medeniyet University, İstanbul, Turkey, tulin.turnuk@medeniyet.edu.tr e Instructor, İstanbul Medeniyet University, İstanbul, Turkey, ilknur.saydam@medeniyet.edu.tr
\end{abstract}

To cite this article: Denkci Akkaş, F., Aydın, S., Baştürk Beydilli, A., Türnük, T. \& Saydam, İ. (2020). Test anxiety in the foreign language learning context: A theoretical framework. Focus on ELT Journal (FELT), 2(1), 4-19. https://doi.org/10.14744/felt.2020.00014

\begin{abstract}
While test anxiety is a strong predictor that affects the achievement and proficiency in the foreign language learning process, how it relates to the current theories and hypotheses remains an unanswered question. In addition, while test anxiety within the scope of descriptive and correlational studies is an issue that has attracted researchers, its theoretical background is mostly ignored. Thus, this paper aims to present a theoretical framework of test anxiety in the foreign language learning context. For this purpose, the paper first introduces the terms, definitions, concepts, theories, and hypotheses concerning test anxiety. Then, the paper focuses on foreign language anxiety. Finally, it presents a theoretical background for test anxiety in a narrower scope. The paper concludes that more research is warranted, whereas teachers need to be trained to moderate the effects of test anxiety among foreign language learners.
\end{abstract}

Keywords:

English as a foreign language test anxiety theoretical framework

Received : 29 February 2020
Revised : 28 March 2020
Accepted : 06 April 2020
Published : 22 June 2020

Published : 22 June 2020

\section{Introduction}

Research shows that test anxiety has adverse effects on the foreign language learning process and achievement and proficiency among foreign language learners, whereas it decreases learning potential (Julkunen, 1992). In addition, it constitutes a barrier to reflecting real performance among foreign language learners. More importantly, research indicates that test anxiety is one of the sources that create psychological and physical problems, cause amotivation and demotivation, decrease interest in foreign language learning, and finally increase the number of mistakes during the production process (Aydin et al., 2006). On the other hand, studies that focus on test anxiety mainly lack the theoretical background of test anxiety. Furthermore, how test anxiety is related to the current theories and hypotheses remains an unanswered question. Thus, the current paper 
aims at presenting the theoretical framework of test anxiety in the foreign language learning process. The paper first introduces terms, definitions, concepts, theories, and hypotheses regarding test anxiety. In other words, after defining anxiety in the broadest perspective, foreign language anxiety is discussed. Then, after categorizing the elements of foreign language anxiety, test anxiety is introduced in the foreign language learning context.

\section{Anxiety}

Learning among human beings is investigated in two major domains as affective and cognitive. The affective domain involves emotions, feelings, and values that guide an individual's perceptions of a learning effort. Thus, it has an indirect but significant impact on the learning outcomes (Boyle et al., 2007). As one of the substantial constituents in the affective domain, anxiety has always remained on the agenda of educational research as in many other fields of study. In other words, researchers have been striving to understand its construct and how it governs human behavior (Spielberger, 2013; Spielberger, 1972). To conclude, it is a powerful emotion that deserves the attention of the academy.

Anxiety is a concept that has derived from the Latin word anxietatem which in the $1500 \mathrm{~s}$ meant apprehension caused by danger, misfortune, or error; uneasiness of mind respecting some uncertainty; a restless dread of some evil. It is seen that the concept is still used to refer to a similar emotional state or a psychological disorder: a feeling of worry, nervousness, or unease about something with an uncertain outcome or a nervous disorder marked by excessive uneasiness and apprehension, typically with compulsive behavior or panic attacks. Anxiety was an object of interest even in the Ancient Times when wellknown philosophers like Aristoteles pondered over the phenomenon. It was stated that anxiousness arose in the anticipation of an evil being poverty, disease, or death. It was also believed that the talent to control this feeling was enough to confirm one's courage. However, during the Middle Ages rather religious and mythical conceptualizations replaced this perspective. Accepted as a physical or a psychological disorder rather than a natural human feeling, anxiety was under scientific investigation thanks to the studies of various researchers like Darwin in the $19^{\text {th }}$ and Freud in the $20^{\text {th }}$ century. With the advent of psychology as an independent field of science, new behavioral and cognitive mindsets were created to approach anxiety and the second half of the $20^{\text {th }}$ century viewed this condition as an illness that required drug therapy (Horwitz, 2013, Spielberger, 1972).

Anxiety is perceived as a different form or an excessive level of fear that one develops against a potential threat or danger. It is such a strong feeling that it may manifest itself with such physical and subjective reactions as swelter, blush, and increase in heart rate or tension (Riskind \& Rector, 2018) in addition to negative feelings like apprehension, tension, and dread (Spielberger, 1972). It tends to emerge in unsafe and dubious social settings (Horwitz, 2013). To put it simply, anxiety is defined as an unpleasant emotional condition associated with feelings of uneasiness, worry, discomfort and dread (He, 2018; Riskind \& Rector, 2018; Spielberger, 1972). For this reason, anxious individuals are usually aware of their unpleasant emotions and capable of providing verbal descriptions for 
the depth and length of these feelings (Spielberger, 1972). Anxiety has also been a trendy research topic due to its strong relation with performance (Carrier et al., 1984; Ng \& Lee, 2015). It can be noted that there exists an inverted $U$ shape relation between the two. For instance, too much or too little anxiety results in low performance, whereas it can be increased with an optimum level of anxiety (Arent \& Landers, 2003; He, 2018; Raglin \& Hanin, 2000). Thus, anxious individuals tend to perceive the case in their hands as difficult, threatening, or challenging and regard themselves as inefficient to cope with that. As a result, they are likely to get fixed with negative sides of the process and its undesirable consequences for themselves. So, they predict failure and loss of self-esteem and approval by their community (Sarason \& Sarason, 1990; Zeidner, 1998).

\section{Trait, state, and situation-specific anxiety}

Spielberger (1972) distinguishes emotional traits and states. He defines traits as relatively enduring individual differences among people in specifiable tendencies to perceive the world in a certain way and/or in dispositions to react or behave in a specified manner with predictable regularity (Spielberger, 1972, p. 31), whereas an emotional state occurs at a time with a specific level of intensity. Trait anxiety refers to a permanent personality disposition and so it is rather stable and predictable, whereas state anxiety identifies a rather temporary emotional condition that changes according to the perceived danger in a circumstance. State anxiety could reflect one's trait anxiety as well (Quigley et al., 2012; Spielberger, 1972) and Ellis (1999) proposes that it is a mixture of trait and situationspecific anxiety which shows up in very specific situations like taking a test, speaking to a native speaker or flying (Ellis, 1999, p. 480).

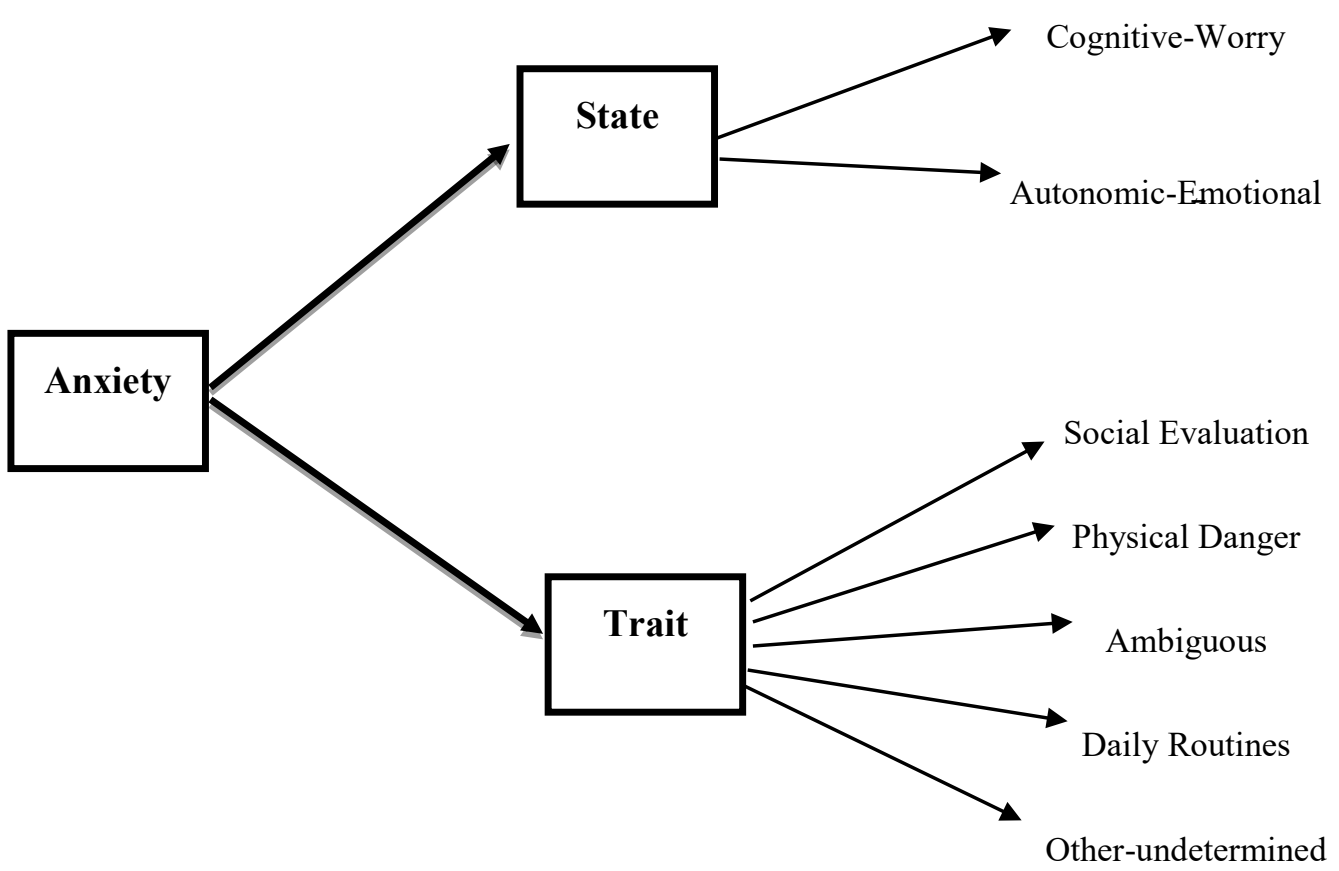

Figure 1. The multidimensionality of state and trait anxiety

(Endler \& Kocovski, 2001, p. 234) 
Endler and Kocovski (2001) argue that there are four components of state anxiety: social evaluation, physical danger, ambiguous, and daily routines. Likewise, trait anxiety is made up of two elements that are cognitive-worry and autonomic-emotional. They have visualized the construct of the two concepts as in Figure 1 above.

Proposed by Alpert and Haber (1960), the second categorization for anxiety as facilitating and debilitating is directly linked to its relationship with performance (Ellis, 1999). Facilitating anxiety leads to a good performance whereas debilitating anxiety is considered an obstacle for achievement (He, 2018). This distinction is generally used for academic or physical performance, and naturally for test achievements and competitions. It helps one do better in a test or competition since it motivates him to fight and keeps him alert, while debilitating anxiety may cause failure as it leads him to avoid or give up striving (Brown, 2007; Ellis, 1999; Zeidner, 1998). Oxford (1999) specifies the direct and indirect effects of debilitating anxiety on learning and argues that a student may perform poorly due to worry or self-doubt generated by debilitating anxiety or may directly reduce participation in teaching activities which will naturally result in underachievement.

\section{Foreign Language Anxiety}

Even though there is considerable research showing that anxiety may promote learning in certain cases (Oxford, 1999), Horwitz et al. (1986) state it is the root for mental blocks against learning a foreign language for ones who can easily achieve their learning goals in other areas like math or science but not in acquiring a second language. They associate this failure with a sort of state or situational anxiety stating that this negativity is typically experienced owing to stressful classroom situations rather than a personality trait (Aydın, 2009; Bekleyen, 2004; Horwitz, 2001; Horwitz et al., 1986).

Foreign language anxiety (FLA) refers to a distinct complex of self-perceptions, beliefs, feelings, and behaviors related to classroom language learning arising from the uniqueness of the language learning process (Horwitz et al., 1986, p. 128). People with FLA experience feelings of dread and worry when they are supposed to use a foreign language particularly in a classroom setting. Within this scope, FLA is considered a significant obstacle for foreign language learners since it decreases their motivation and classroom participation. Moreover, learners who suffer from FLA tend to become defensive. Thus, they prefer avoiding their foreign language to get rid of negative feelings (He, 2018).

Ellis (1999) asserts that anxiety has the power to determine the quality and quantity of input, processing, and success in the outcome (Williams \& Andrade, 2008). This assertion is also supported by Krashen's Comprehensible Input and Affective Filter Hypotheses (Brown, 2007). Krashen (1985) argues that comprehensible input is the precondition for successful language acquisition and that it refers to meaningful input that is slightly beyond the learner's current competence which is termed as " $i+1$ ". The learner is expected to advance with the moderate challenge provided in input but still grasps the message in it. It is also suggested that speaking will emerge at the point when the learner has received enough input (Brown, 2007). However, the learner can benefit from the comprehensible 
input properly only in the presence of a low affective filter (Du, 2009; Pierce, 1995). In other words, the learner needs to lower the affective filter to let the input in (Aydin, 2019; $\mathrm{Du}, 2009)$. Otherwise, she may not be able to take in the input that is blocked by the affective filter (Aydın, 2019; Ni, 2012); this may lead to an interruption in the language learning progress (Horwitz et al., 1986). According to the theory, the affective filter comprises certain emotions as motivation, self-confidence, attitudes, and anxiety. Therefore, someone with high levels of motivation, self-confidence, positive attitudes, and reduced anxiety can lower his/her affective filter and get rid of the potential psychological barriers (Aydin, 2019; Ni, 2012). FLA occurs more often in formal settings where adults learn their foreign language consciously rather than acquiring it in informal contexts. They can monitor their output as they are conscious of the rules and patterns that are explicitly taught which may increase their affective filter and so anxiety (Scovel, 1978). In short, FLA that is a significant component of the affective filter is regarded to have a negative effect on foreign language learning (Horwitz, 2001); therefore, it is important to understand its nature and find out efficient ways to cope with it. Some language teaching methods like Silent Way, Suggestopedia, and Community Language Learning were developed in the late $20^{\text {th }}$ century and these methods were promising to use techniques that would lower the affective filter to provide a supportive and non-threatening environment for language learners (Scovel, 1978).

Horwitz et al. (1986) suggest that FLA is constituted by the combination of the following three components that are briefly described below: communication apprehension, fear of negative evaluation and test anxiety (Aydin, 2019; Williams, 1991). Communication apprehension identifies a type of shyness characterized by fear or anxiety about communicating with people (Horwitz et al., 1986, p. 127). People with communication apprehension are unwilling to have social interactions with others and tend to drop out conversations (Beatty \& Pascual-Ferrá, 2016). This is also observable in foreign language classrooms where students may exhibit reluctance to communicate in the target language due to their limited language proficiency, lack of efficient communication skills, and restricted capacity to express themselves (Aida, 1994). Although they have sophisticated ideas that they can talk about in their mother tongue effortlessly, students cannot express them due to the limitation in their immature L2 which creates frustration, anger, and worry and so increases their self-consciousness and anxiety (Horwitz, 2001; MacIntyre \& Gardner, 1989; Williams, 1991). Fear of negative evaluation is basically about the social impression people create in their community and refers to the apprehension for being perceived and judged unfavorably by others (Carleton et al., 2006; Leary, 1983). The anticipation for negative evaluation and the fear of creating a poor image in the community will increase anxiety and bring in avoidance behaviors (Leary, 1983). As foreign language learners are afraid of being evaluated negatively by their teachers or more proficient peers, they want to save their social image and become sensitive to making mistakes or producing poor quality language (Horwitz et al., 1986). Test anxiety is directly related to academic evaluation (MacIntyre \& Gardner, 1989). Students who are afraid of exhibiting low performance in assessment situations develop test anxiety which is typical for foreign language classrooms as well (Aida, 1994). Test anxiety refers to the stress, uneasiness, and 
worry one feels when his performance is evaluated; that is, it is a term that describes the fear of failure in a test. People tend to develop test anxiety because they are not satisfied with their preparation before the evaluation or they are dubious of their abilities or performance during the assessment (McDonald, 2001). Below, test anxiety is discussed in detail.

\section{Test anxiety}

Tests are inevitable elements in academic life. Starting from kindergarten, people are to take various tests like entrance exams, classroom exams or proficiency exams for the continuation of their education or such specific tests such as a driving license exam to get authorization for a basic activity in their daily life (Goonan, 2003). It has been a common research subject both in psychology and education and gained popularity since the beginning of the $21^{\text {st }}$ century (Putwain, 2008; Zeidner \& Matthews, 2002; Zeidner, 1998) although there was a considerable amount of research in the late $20^{\text {th }}$ century as well (Stöber \& Pekrun, 2004). The main reason for this growing interest is the proliferation of standardized tests which are a part of American and British educational policies to determine student and school performance and to indicate accountability, while there has been severe criticism for this overemphasis on testing in such educational systems since students who perceive these exams as formidable objects that endanger their welfare suffer from serious test anxiety (Goonan, 2003; Putwain, 2008).

Test anxiety is the set of cognitive, physiological, and behavioral responses that accompany concern about possible negative consequences or failure on exams or similar evaluative situations (Zeidner, 2007, p. 166). It creates excessive amounts of concern, worry, and fear about negative evaluation during or in anticipation of performance or evaluative situations (Goonan, 2003, p. 258). Individuals are afraid of getting embarrassed by their unsatisfactory performance since they consider it as a threat for their ego or selfesteem (Goonan, 2003; Putwain, 2008; Sapp, 1999) and consequently, they either avoid evaluative situations or experience excessive stress if they cannot flee from being tested (Sarason, 1978). Their academic performance is hurt in either case (Goonan, 2003; MacIntyre \& Gardner, 1989). Test anxiety appears in specific situations or contexts where one's performance is being evaluated and it has an evident social aspect due to the concerns with how that performance will be judged by the others (Putwain, 2008). This may also endanger the validity of the test since the score a student gets in the test may also indicate her capability of coping with stress and anxiety in that evaluative situation rather than signifying achievement of the intended exam goals (Zeidner, 2007; Zeidner, 1995).

When the construct of test anxiety is regarded, it is seen that there is severe ambiguity since various researchers have conducted their studies focusing on different meanings of test anxiety. The concept has been associated with close but distinct constructs like stressful evaluative stimuli and contexts, trait anxiety, and state anxiety (Zeidner, 1998). At the onset of studies on test anxiety as an independent notion in the 1950s, its relationship with performance was investigated and the Test Anxiety Questionnaire and the Test Anxiety Scale for Children were the primary tools to collect data (Stöber \& Pekrun, 2004). Today, 
it is accepted that test anxiety interferes with task performance; on the other hand, it is recognized that there are other factors like study skills and motivation which may alter performance as well (Sapp, 1999).

In the $60 \mathrm{~s}$ and $70 \mathrm{~s}$, the discussions went on under two main conceptualizations. The first debate was on viewing test anxiety as a kind of trait or state anxiety (Hembree, 1988; Stöber \& Pekrun, 2004). Researchers tried to understand whether test anxiety was a part of one's stable personality trait or a transitory emotional state (Zeidner, 1998). The stance for the trait view proposes that test anxiety is a permanent individual difference which varies according to how one perceives the threat in test-taking occasions in general. It is also argued that this personal disposition is developed through past experiences in the family and/or with failure in academic life which may not be only the result but also the source of test anxiety (Putwain, 2008), while the proponents of the state perspective suggest that it is also possible for a learner to experience test anxiety in a singular case perceiving that specific situation as a threat to her ego (Zeidner, 1998). This type of test anxiety is contextspecific since a student with low trait test anxiety may develop a high degree of state test anxiety in such particular assessment situations (Putwain, 2008).

The second approach regards test anxiety as a combination of two cognitive and affective dimensions which are worry and emotionality (Liebert \& Morris, 1967; Stöber \& Pekrun, 2004; Zeidner, 1998). Being the cognitive counterpart, worry is directly connected with one's anticipation for failure or success. One does not think about the outcomes of failure if she predicts accomplishment for her performance in a test which eventually lowers the degree of test anxiety (Liebert \& Morris, 1967). Emotionality which is the affective dimension refers to one's doubt about her actual performance in a particular test. This view signifies a direct correlation between the levels of test anxiety and uncertainty about test achievement (Liebert \& Morris, 1967). However, Liebert and Morris' research revealed a stronger relationship between test performance and the cognitive component of test anxiety which also concluded a weaker connection with emotionality (Zeidner, 1998). Just like Liebert and Morris, Wine (1971) developed a cognitive model for test anxiety considering its debilitating effects on performance. Named as the cognitive-attentional or interference model (Zeidner, 1998, p. 10), this approach highlights the advantage of low test-anxious people over high test-anxious ones. This advantage mainly stems from low test-anxious people's ability to get fully concentrated on task-relevant issues during a test whereas high test-anxious people have to allocate their attention to internal processes like self-evaluative, self-deprecatory thinking, and perception of autonomic responses" in addition to the taskrelevant issues (Wine, 1971, p. 92). Since high test-anxious individuals are engaged with such intrusive thinking while taking a test, they inevitably end up with poor performance and obviously, their success diminishes depending on the complexity of the test task (Hembree, 1988; Sarason \& Sarason, 1990; Wine, 1971; Zeidner, 1998).

From the 70 s to the early $80 \mathrm{~s}$, applied research in test anxiety flourished seeking treatment and effective techniques like attentional training, stress inoculation, systematic cognitive restructuring or studies skills counseling to diminish its debilitating consequences (Zeidner, 1998, p. 11). However, all those studies eventually arose severe criticism against the cognitive-attentional model since it was revealed that treatment did not improve 
students' performance in tests although it helped to reduce their anxiety (Kirkland \& Hollandsworth, 1980; Zeidner, 1998). The point is that students perform poorly due to their lack of proper study and test-taking skills and the ones who suffer from this deprivation are mostly high test-anxious students. In other words, high test-anxious students cannot learn the material adequately since they cannot study effectively (Culler \& Holahan, 1980; Mealey \& Host, 1992; Sapp, 1999). These students also have serious trouble in learning, organizing, and retrieving new information in test-taking situations (Benjamin et al., 1981; Sapp, 1999). In a nutshell, test anxiety debilitates performance by reducing the cognitive capacity available for task solution, and study or test-taking skills facilitate learning and test performance by reducing the cognitive capacity demanded by different tasks (Tobias, 1985, p. 135).

The late $80 \mathrm{~s}$ and $90 \mathrm{~s}$ witnessed a boom of test anxiety research dealing with various theoretical models and their causal relations with test performance concerning information processing phases (Zeidner, 1998). One of the prominent figures in that era was Sarason who conceptualized test anxiety as a construct with four interrelated components: tension, worry, test-irrelevant thought and bodily reactions (Sapp, 1999; Sarason \& Sarason, 1990; Sarason, 1984). Another theory that is still well accepted is the Transactional Process Model presented by Spielberger and Vagg in 1995 (Sapp, 1999; Spielberger \& Vagg, 1995; Zeidner, 1998). This comprehensive model points out the functional relations between state emotions and test anxiety over time (Ringeisen \& Buchwald, 2010, p. 432) and accordingly, test anxiety is regarded as a situation-specific case that is experienced due to a trait stimulated by state anxiety, worry, and emotionality (Sapp, 1999). This model intends to explain the antecedent conditions and dispositions that influence students' reactions to tests, the mediating emotional and cognitive processes involved in responding to evaluative situations and the correlates and consequences of test anxiety (Spielberger \& Vagg, 1995, p. 11). It is argued that there is constant and active interaction among the components of test anxiety, so the test taker and the testing situation are interrelated. Additionally, some people are better at managing anxiety than others (Sapp, 1999). Considering the transactional aspects of the previous test anxiety literature, Zeidner (1998) suggested an integrative transactional model that is visualized in Figure 2. 


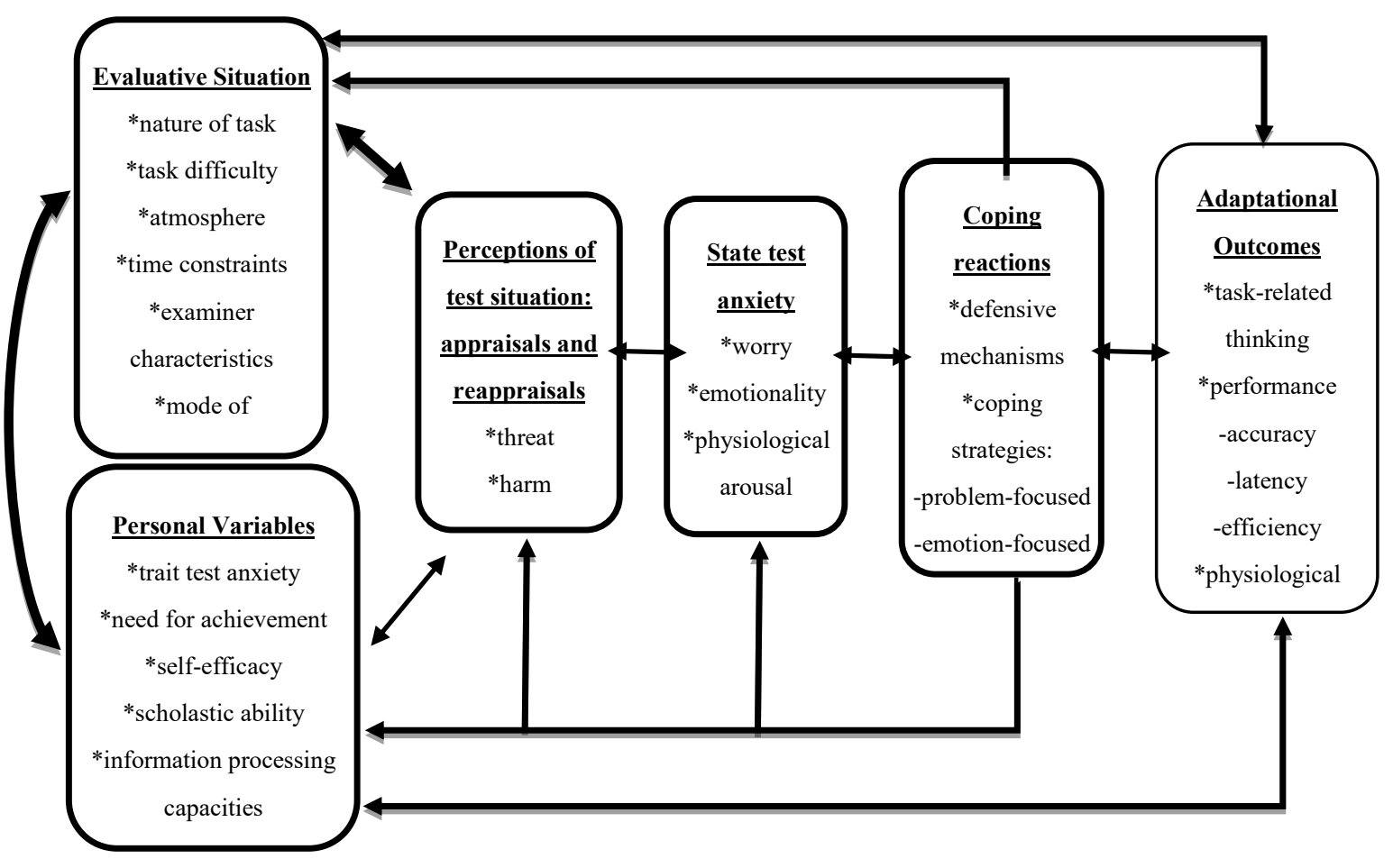

Figure 2. The transactional model of test anxiety (Zeidner, 1998, p. 19)

As can be understood from the figure, Zeidner's conceptualization presents a reciprocal and dynamic model in which all the components of test anxiety are in constant and mutual interaction. The fundamental constructs of test anxiety involve evaluative situations, personal variables, perceptions of test situations, state test anxiety, coping reactions, and adaptive outcomes (Zeidner, 1998).

\section{Evaluative situations}

First, the level of test anxiety experienced by a learner is determined by such elements in the evaluative situation as the nature of task, task difficulty, atmosphere, time constraints, examiner characteristics, and administration mode. Individuals may get more stressed when the test task is complicated or unfamiliar to them or when they are given very limited time to complete the test (Zeidner, 1998). Moreover, things get tougher for a learner who has to cope with ambiguity due to his/her lack of adequate knowledge about the testing context.

\section{Personal variables}

People do not get worried equally about a particular evaluative situation, so they may feel different levels of challenge and threat within the same testing context. It is possible to explain this variation as "a situation-specific form of trait anxiety" (Zeidner, 1998, p. 22). Individuals with high trait anxiety are likely to view an evaluative situation more 
frightening and stressing than ones with low trait anxiety; they tend to get hurt more intensely and frequently in testing situations.

\section{Perceptions of test situation}

Their cognitive perceptions act as a mediator between individuals and contexts. In the case of a test situation, their emotions and behaviors are guided by their personal judgment of that particular evaluative condition. How they feel and behave mostly depends on their "subjective appraisal of the situation" (Zeidner, 1998, p. 22). This implies that it is not the situation itself but the way it is interpreted by an individual that evokes anxiety. According to Zeidner (1998), people are apt to get anxious if they regard a test situation as egothreatening or harmful; moreover, this anxiety increases if they think they are incapable of coping with such cases. People may notice a threat in a test situation due to their expectation for such risks as social disapproval or resitting a test. Likewise, they may not get anxious at all if only the threat or danger in the context goes unrecognized by them. Moreover, challenges in an evaluative situation, prior experience, awareness of possible outcomes, the judgment of expenses and individual variations shape cognitive appraisals that stimulate anxiety (Zeidner, 1998).

\section{State test anxiety}

This term is used for "the transitory, anxious affect state provoked by a specific evaluative situation" (Hong \& Karstensson, 2002, p. 349). In such cases, people are drifted to feel tense and get incited. Besides, their autonomic nervous system is activated which results in physiological arousals like trembling, sweating or irregular blood pressure. They also end up with concerning about failure, being thoughtful, and losing their self-confidence.

\section{Coping reactions and adaptive outcomes}

People react to a test situation to reduce or tolerate the stress they feel as a result of their interaction with the environment. They apply some problem-oriented, curative, avoidance, or defensive strategies to regulate their emotional state and to manage their anxiety (Zeidner, 1998). Having reviewed the previous research on coping reactions and adaptive outcomes, Zeidner (1995, p. 130-132) suggests the following generalizations:

1. Adaptive coping in exam situations involves a flexible repertoire and combined use of alternative coping strategies.

2. Coping with a stressful exam situation is a process; it is a transaction between a person and an event that plays across time and changing circumstances.

3. Coping strategies in exam situations are found to work with modest effects with some people and some outcomes.

4. Coping patterns should match both the context and the individual.

5. Coping strategies vary between and within individuals.

6. Coping responses are not uniformly adaptive. 
7. Causal relations among coping strategies and outcome indices are likely to be multidirectional rather than linear.

Another conceptualization for test anxiety appeared with the application of the SelfRegulative Theory of anxiety and competence to test anxiety (Zeidner, 2007; Zeidner \& Matthews, 2005). As depicted in Figure 3, the model specifies the significance of transactional processes and self-referent information (Zeidner, 2007).

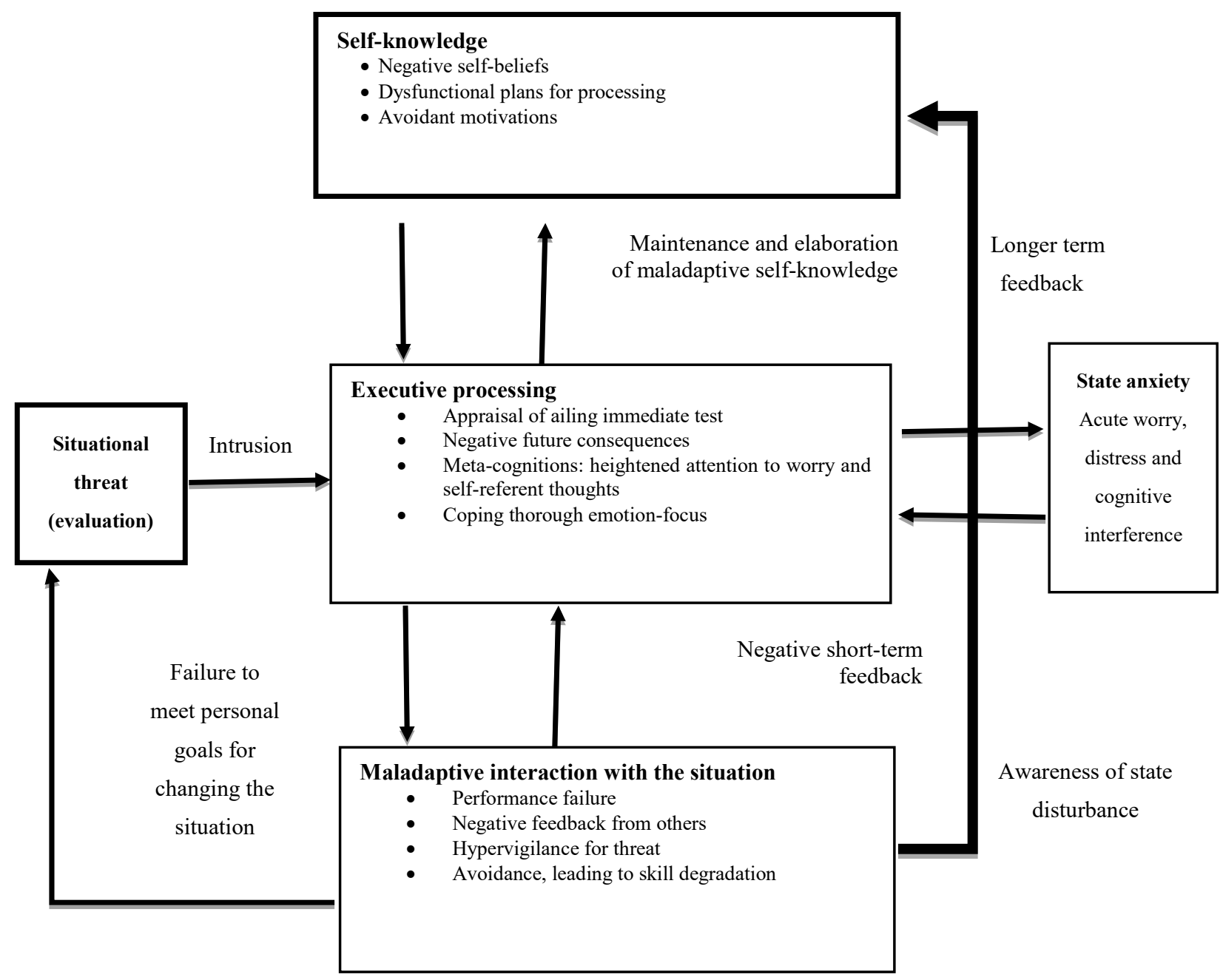

Figure 3. A prototypical self-regulative model for evaluation anxiety

(Zeidner \& Matthews, 2005, p. 154)

Figure 3 illustrates that self-regulative processing is activated by an intrusion which may refer to the thought of potential failure in a testing situation. With the activation, the system begins to search for a proper way to cope with it. This search is largely influenced by self-knowledge, and if negative self-beliefs are fetched, an increase in test anxiety occurs. The individual focuses on his/her poor performance and negative feedback. She gets extremely alert for danger, starts to accuse herself of being incompetent, and tends to exhibit avoidance behaviors. This type of processing eventually triggers state anxiety causing distress and cognitive interference. Normally, an individual is expected to 
restructure his/her self-knowledge by learning from each evaluation experience and by adding more efficient coping strategies to his/her repertoire. However, constant worry may prevent one from such a beneficial update in the self-knowledge and direct her to avoid evaluative situations. Such avoidance is hazardous as it reduces the chances for modification in the coping strategies for better (Zeidner, 2007; Zeidner \& Matthews, 2005).

Despite the slowdown after the $90 \mathrm{~s}$, test anxiety has continued to remain a popular research topic to date (Zeidner, 1998). This popularity mainly stems from the fact that the relation between test anxiety and performance/achievement arises interest in educational psychology as well as in all other branches of applied psychology. Today, it is known beyond any doubt that test anxiety is related to "students' achievement at school, their school-related motivation, academic self-concepts, career advancement, personality development, and health" (Stöber \& Pekrun, 2004). This is specifically significant in Western communities with competitive educational systems in which tests play crucial roles in the course of every individual's life (Zeidner, 2007). In short, it is of paramount importance to understand the construct of test anxiety, to develop a reliable tool to measure it and to reveal its relations with various factors in educational settings.

\section{Conclusions and Discussion}

In the broadest sense, it can be stated that learning among human beings is directly related to affective domain. Within the scope of the affective domain, anxiety can be seen as a feeling of worry and nervousness stemmed from trait, an uncertain state or situation. Trait anxiety relates to a permanent personality disposition, whereas state anxiety refers to a rather temporary emotional condition that changes according to the perceived danger. Last, situation-specific anxiety shows up in very specific situations. Anxiety can be also categorized as facilitating and debilitating when its effects are considered. Facilitating anxiety is a source of good performance while debilitating anxiety is considered an obstacle for achievement.

FLA can be defined as a complex combination of feelings, beliefs, behaviors, and selfperception within the foreign language learning process. It should be noted that FLA has adverse effects on learners' motivation and classroom participation and results in avoidance of foreign language. Moreover, it has the power to determine the quality and quantity of input, processing, and output within the scope of affective filter that is suggested in the Comprehensible Input and Affective Filter Hypotheses. FLA consists of three elements. First, communication apprehension is a kind of shyness and fear resulting in communication in the target language. Second, fear of negative evaluation is the fear regarding social impressions in the community. Finally, test anxiety can be defined as the fear of showing low academic performance in assessment situations.

Test anxiety, as defined above, is the set of behavioral, psychological, and cognitive reactions to tests regarding failure, negative consequences, and evaluative situations. The concept can be associated with trait anxiety and state anxiety. On the other hand, it is also possible to state that it falls under the category of situation-specific anxiety. In other words, 
it can be noted that test anxiety is a permanent individual disposition stemmed from past experiences in academic life, whereas it can be experienced in a singular state. Moreover, test anxiety can be perceived in specific situations. While the current literature suggests that test anxiety is provoked by personality, states or situations, it can be seen as a combination of worry, a direct connection to failure and success, and emotionality, referring doubt about actual performance. Within this scope, the cognitive-attention or interference can be highlighted in terms of the advantage of low test-anxious people who concentrate on task-relevant issues during tests, while high test-anxious people allocate their attention to internal processes such as self-evaluative, self-deprecatory thinking, and perception of autonomic responses. Yet, the cognitive-attentional model can be criticized, as test anxiety may be a result of the low level of achievement due to poor test-taking and study skills. To conclude, it is possible to state that test anxiety is not the only variable that may increase or decrease the level of achievement in the target language; however, it may be both the cause of and effect on the achievement in the target language.

Test anxiety is still researched and discussed regarding its causal relations with test performance. Within this perspective, it can be noted that test anxiety involves four interrelated components, namely tension, worry, test-irrelevant thought, and bodily reactions. Besides, the Transactional Process Model suggests that there exist functional relations between state emotions and test anxiety. Moreover, the constructs of test anxiety involve evaluative situations, personal variables, perceptions of test situations, state test anxiety, coping reactions, and adaptive outcomes. First, evaluative situations can be listed as the nature of task, task difficulty, atmosphere, time constraints, examiner characteristics, and administration mode, whereas personal variables can be a combination and variation of a situation-specific form of trait anxiety. Second, perceptions of test situation can be clarified within the scope of a mediator between individuals and contexts, test situations, emotions, and behaviors, whereas state test anxiety is provoked by a specific evaluative situation. Third and last, coping reactions and adaptive outcomes include several problemoriented, curative, avoidance or defensive strategies to regulate learners' emotional state and to manage their anxiety. As a final note, it can be added that self-regulative processing is activated by an intrusion which may refer to the thought of potential failure in a testing situation.

Several recommendations can be noted. In the broadest perspective, foreign language teachers should raise their awareness of test anxiety. Speaking more specifically, teachers should know that affect is one of the inseparable domains of foreign language learners and anxiety, one of the affective states, relates to trait, states, and situations. In addition, they should know that anxiety has both facilitating and debilitating effects on the language learning process. Within the scope of FLA, they should be aware that anxiety may cause avoidance of foreign language learning. In the narrowest perspective, they should also know that FLA is a combination of communication comprehension, fear of negative evaluation, and test anxiety. Foreign language teachers should be also aware that learners show cognitive and psychological reactions to tests. Thus, they need to develop strategies regarding decreasing the level of fear of failure and designing evaluative situations. Furthermore, they should know how to analyze the sources of test anxiety, as it may be 
provoked by personality, states, and specific situations. Teachers should also train their students in terms of motivation, concentration, and facilitative effects of a moderate level of test anxiety. They should also develop strategies and tactics on how to cope with tension, test-irrelevant thoughts, and body reactions among learners. Within this scope, teachers should be aware that stressful exam situations involve a process that depends on changing circumstances, whereas they should know that coping patterns among learners relate to the context and individual differences. In other words, they should be informed that coping with test anxiety may not be uniformly adaptive and that it is multidirectional (Zeidner (1995). As a note, given that teachers may have a considerable role in moderating the level of test anxiety, reducing debilitative effects, and increasing facilitative effects, they should be trained about anxiety and related issues throughout preand in-service teacher education programs. Within this scope, both pre- and in-service teacher education programs should involve the above-mentioned issues. As a final note, it should be added that these improvements can be realized by program developers and policymakers who need to use research results to modify the mentioned programs.

A few recommendations can be also noted for further research. More research on test anxiety in the foreign language learning context is necessary, as the current literature does not present a consensus on the causes and effects of test anxiety. For this purpose, there is a strong need to perform qualitative studies for a deeper understanding of test anxiety. Moreover, new tools should be developed to measure the levels of test anxiety in various foreign language education contexts. Researchers should also tend to perform descriptive, and correlational and experimental studies in terms of clarifying the relationships between test anxiety and various factors.

\section{Disclosure Statement}

This study was supported by the Unit of Scientific Research Projects of Istanbul Medeniyet University through the research grant (S-GAP-2019-1491) under the title of Test Anxiety among Foreign Language Learners. The authors would like to thank Istanbul Medeniyet University for funding and scholarship.

\section{References}

Aida, Y. (1994). Examination of Horwitz, Horwitz, and Cope's construct of foreign language anxiety: The case of students of Japanese. The Modern Language Journal, 78(2), 155-168.

Arent, S. M., \& Landers, D. M. (2003). Arousal, anxiety, and performance: A reexamination of the invertedU hypothesis. Research Quarterly for Exercise and Sport, 74(4), 436-444.

Aydın, S. (2009). Test anxiety among foreign language learners: A review of literature. Journal of Language and Linguistic Studies, 5(1), 127-137.

Aydin, S. (2019). Affective states and learning outcomes in EFL education. In Preparing teachers for a changing world: Contemporary issues in EFL education, Ed. S. Çelik, Ankara: Vize Publications, p. 151-164.

Aydın, S., Yavuz, F., \& Yeşilyurt, S. (2006). Test anxiety in foreign language learning. Journal of Graduate School of Social Sciences of Balikesir University, 9(16), 145-160.

Beatty, M. J., \& Pascual-Ferrá, P. (2016). Communication apprehension. In The international encyclopedia of interpersonal communication, Eds. Charles R. Berger and Michael E. Rolof, UK: John Wiley \& Sons, p. 1-9. 
Bekleyen, N. (2004). Foreign language anxiety. Journal of Graduate School of Social Sciences of Çukurova University, 13(2), 27-39.

Benjamin, M., McKeachie, W. J., Lin, Y. G., \& Holinger, D. P. (1981). Test anxiety: Deficits in information processing. Journal of Educational Psychology, 73(6), 816-824.

Boyle, A., Maguire, S., Martin, A., Milsom, C., Nash, R., Rawlinson, S., Turner, A., Wurthmann, S. \& Conchie, S. (2007). Fieldwork is good: The student perception and the affective domain. Journal of Geography in Higher Education, 31(2), 299-317.

Brown, H. D. (2007). Principles of language learning and teaching. USA: Pearson Education.

Carleton, R. N., McCreary, D. R., Norton, P. J., \& Asmundson, G. J. (2006). Brief fear of negative evaluation scale-revised. Depression and Anxiety, 23(5), 297-303.

Carrier, C., Higson, V., Klimoski, V., \& Peterson, E. (1984). The effects of facilitative and debilitative achievement anxiety on notetaking. The Journal of Educational Research, 77(3), 133-138.

Culler, R. E., \& Holahan, C. J. (1980). Test anxiety and academic performance: The effects of study-related behaviors. Journal of Educational Psychology, 72(1), 16-20.

Du, X. (2009). The affective filter in second language teaching. Asian Social Science, 5(8), 162-165.

Ellis, R. (1999). The study of second language acquisition. USA: Oxford University Press.

Endler, N. S., \& Kocovski, N. L. (2001). State and trait anxiety revisited. Journal of Anxiety Disorders, 15(3), 231-245.

Goonan, B. (2003). Overcoming test anxiety: Giving students the ability to show what they know. In Measuring up: Assessment issues for teachers, counselors and administrators, Ed. J. E. Wall \& G. R. Walz, US: Caps Press, p. 257-277.

He, D. (2018). Foreign language learning anxiety in China: Theories and applications in English language teaching. Singapore: Springer.

Hembree, R. (1988). Correlates, causes, effects, and treatment of test anxiety. Review of Educational Research, 58(1), 47-77.

Hong, E., \& Karstensson, L. (2002). Antecedents of state test anxiety. Contemporary Educational Psychology, 27(2), 348-367.

Horwitz, A. V. (2013). Anxiety: A short history. Baltimore: JHU Press.

Horwitz, E. (2001). Language anxiety and achievement. Annual Review of Applied Linguistics, 21, 112-126.

Horwitz, E. K., Horwitz, M. B., \& Cope, J. (1986). Foreign language classroom anxiety. The Modern Language Journal, 70(2), 125-132.

Julkunen, K. (1992). Trait and test anxiety in the FL classroom. The revised version of a paper presented at a Teaching Symposium, Helsinki, Finland.

Kirkland, K., \& Hollandsworth, J. G. (1980). Effective test-taking: Skills-acquisition versus anxietyreduction techniques. Journal of Consulting and Clinical Psychology, 48(4), 431-439.

Krashen, S. D. (1985). The input hypothesis: Issues and implications. Addison-Wesley Longman Ltd.

Leary, M. R. (1983). A brief version of the fear of negative evaluation scale. Personality and Social Psychology Bulletin, 9(3), 371-375.

Liebert, R. M., \& Morris, L. W. (1967). Cognitive and emotional components of test anxiety: A distinction and some initial data. Psychological Reports, 20(3), 975-978.

MacIntyre, P. D., \& Gardner, R. C. (1989). Anxiety and second-language learning: Toward a theoretical clarification. Language Learning, 39(2), 251-275.

McDonald, A. S. (2001). The prevalence and effects of test anxiety in school children. Educational Psychology, 21(1), 89-101.

Mealey, D. L., \& Host, T. R. (1992). Coping with test anxiety. College Teaching, 40(4), 147-150.

$\mathrm{Ng}$, E., \& Lee, K. (2015). Effects of trait test anxiety and state anxiety on children's working memory task performance. Learning and Individual Differences, 40, 141-148.

Ni, H. (2012). The effects of affective factors in SLA and pedagogical implications. Theory and Practice in Language Studies, 2(7), 1508-1513.

Oxford, R. L. (1999). Anxiety in the language learner: New insights. In Affect in language learning, Ed. J. Arnold, Cambridge: Cambridge University Press, p. 58-67.

Peirce, B. N. (1995). Social identity, investment, and language learning. TESOL Quarterly, 29(1), 9-31.

Putwain, D. W. (2008). Deconstructing test anxiety. Emotional and Behavioural Difficulties, 13(2), 141-155.

Quigley, L., Nelson, A. L., Carriere, J., Smilek, D., \& Purdon, C. (2012). The effects of trait and state anxiety on attention to emotional images: An eye-tracking study. Cognition and Emotion, 26(8), 1390-1411.

Raglin, J. S., \& Hanin, Y. L. (2000). Competitive anxiety. In Emotions in sport, Ed. Hanin, Y. L., USA: Human Kinetics, p. 93-111. 
Ringeisen, T., \& Buchwald, P. (2010). Test anxiety and positive and negative emotional states during an examination. Cognition, Brain, Behavior, 14(4), 431-447.

Riskind, J. H., \& Rector, N. A. (2018). Looming vulnerability: Theory, research and practice in anxiety. UK: Springer.

Sapp, M. (1999). Test anxiety: Applied research, assessment, and treatment interventions. New York: University Press of America.

Sarason, I. G. (1978). The test anxiety scale: Concept and research. In Stress and anxiety, Eds. C. D. Spielberger \& I. G. Sarason, Washington, DC: Hemisphere, p. 193-216.

Sarason, I. G. (1984). Stress, anxiety, and cognitive interference: Reactions to tests. Journal of Personality and Social Psychology, 46(4), 929-938.

Sarason, I. G., \& Sarason, B. R. (1990). Test anxiety. In Handbook of social and evaluation anxiety, Ed. H. Leitenberg, Boston: Springer, p. 475-495.

Scovel, T. (1978). The effect of affect on foreign language learning: A review of the anxiety research. Language Learning, 28(1), 129-142.

Spielberger, C. D. (1972). Anxiety: Current trends in theory and research. New York: Academic Press.

Spielberger, C. D. (2013). Anxiety and behavior. New York: Academic Press.

Spielberger, C. D., \& Vagg, P. R. (1995). Test anxiety: A transactional process. In Test anxiety: Theory, assessment, and treatment, Eds. C. D. Spielberger \& P. R. Vagg, Washington: Taylor \& Francis, p. 314.

Stöber, J., \& Pekrun, R. (2004). Advances in test anxiety research. Anxiety, Stress and Coping, 17(3), 205211.

Tobias, S. (1985). Test anxiety: Interference, defective skills, and cognitive capacity. Educational Psychologist, 20(3), 135-142.

Williams, K. (1991). Anxiety and formal second/foreign language learning. RELC Journal, 22(2), 19-28.

Williams, K. E., \& Andrade, M. R. (2008). Foreign language learning anxiety in Japanese EFL university classes: Causes, coping, and locus of control. Electronic Journal of Foreign Language Teaching, 5(2), 181-191.

Wine, J. (1971). Test anxiety and direction of attention. Psychological Bulletin, 76(2), 92-104.

Zeidner, M. \& Matthews, G. (2002). Test anxiety. In Encyclopedia of psychological assessment, Ed. Fernandez-Ballesteros, London: Sage, p. 964-969.

Zeidner, M. \& Matthews, G. (2005). Evaluation anxiety. In Handbook of competence and motivation, Eds. Andrew J. Elliot \& Carol S. Dweck, New York: The Guilford Press, p. 141-163.

Zeidner, M. (1995). Adaptive coping with test situations: A review of the literature. Educational Psychologist, 30(3), 123-133.

Zeidner, M. (1998). Test anxiety: The state of the art. New York: Kluwer Academic Publishers.

Zeidner, M. (2007). Test anxiety in educational contexts: Concepts, findings, and future directions. In Emotion in education, Eds. Paul A. Schutz \& Reinhard Pekrun, CA: Academic Press, p. 165-184.

\section{Copyrights}

Copyrights for the articles are retained by the author(s), with first publication rights granted to the Journal.

This is an open-access article distributed under the terms and conditions of the Creative Commons Attribution license (CC BY-NC-ND). http://creativecommons.org/licenses/by-nc-nd/4.0/ 